\title{
Design and Implementation of Serial Port Ultrasonic Distance Measurement System Based on STC12
}

\author{
Jian Huang \\ Xijing University, Xi'an 710123, China \\ 565200245@qq.com
}

Keywords: Ultrasonic distance measurement; STC12C5A60S2; Serial port

\begin{abstract}
According to the principle of ultrasonic distance measurement, a kind of ultrasonic distance measurement system with low blind area, low power consumption, high precision and small size is designed and realized in the light of the influence of temperature and air flow. STC12C5A60S2 high performance microcontroller is the main control, improve the overall performance of the system, using DS18B20 as the temperature compensation to improve the accuracy of measurement. In addition, the proposed in ultrasonic ranging module probe are connected according to the echo measurements were carried out, according to the different temperature value to calculate the distance, the measured results of the conversion to digital quantity, and MCU through the serial port for connection method to realize ranging. The hardware circuit is designed and the software is programmed. Test results show that: in the wall, glass, liquid surface and other smooth material conditions, the measurement accuracy is less than one millimeters, the ultrasonic ranging system has the advantages of high precision, low cost, convenient installation and so on. It suitable for high precision measurement in short range ranging.
\end{abstract}

\section{Introduction}

As an efficient, accurate and non-contact detection method, ultrasonic wave is widely used in ranging, speed, welding, cleaning and other fields. In the computer, intelligent equipment, etc., can be used as a distance sensor, as a smart car or robot eyes, can effectively detect the location and distance of obstacles, to achieve ranging and obstacle avoidance. In recent years, the principle of ultrasonic ranging has not changed, but due to the adoption of new techniques, new methods, make the measurement accuracy is greatly improved, is considered to be one of the most effective methods of measuring [1-4].

Factors affect the precision of ultrasonic ranging except the making craft of the sensor itself, but also with the transmitting and receiving performance, and environmental temperature and error correction methods about, so to accurate measurement of ultrasonic propagation time and environmental temperature is the key to realize the accurate location.

This paper choose high performance microcontroller STC12C5A60S2 as a master, the maximum clock crystal up to $24 \mathrm{MHz}$, quick disposal of signal and the accurate timing, with DS18B20 temperature precise measurement, and the ultrasonic propagation speed is selected according to the temperature measurement. Ultrasonic probe the transceiver, the echo signal will be measured by processing module, the conversion to digital quantity, and through the serial port to 9600 baud rate of speed and MCU is connected, to achieve high-speed data acquisition, will eventually be collected data conversion for the distance value display on the 1602 liquid crystal module, the error can be controlled within $1 \mathrm{~mm}$.

\section{The Principle of Ultrasonic Distance Measurement}

Ultrasonic wave is independent of velocity and frequency in a large range of frequency, the wave propagation direction is the same as the vibration direction, and it is the elastic mechanical wave of the longitudinal vibration. The commonly used ranging method, pulse echo method, its working principle is using impulse excitation of ultrasonic emission then receives echo signals, through the detection of pulses from the transmitter to the receiver to echo the time $t$, according to the formula 
$\mathrm{s}=\mathrm{v} \mathrm{t} / 2$ calculated distance measurement [5-7].

\section{Hardware Circuit Design}

System hardware circuit design as shown in Fig. 1, the macro crystal technology, high performance microcontroller stc12c5a60 as a master, crystal with $24 \mathrm{MHz}$ to improve the performance of the system, using the serial port RXD and ultrasonic module is connected with the collected to measure the distance signal; MCU P26 connection DS18B20, and connect a 4.7K pull-up resistor current temperature acquisition by single bus communication with the MCU, according to the serial data and temperature value to calculate the distance, and the results show in 1602.



Figure 1. System hardware connection diagram

STC12C5A60S2 Microcontroller Introduction. STC12C5A60S2 MCU is macro crystal technology, production of single clock / machine cycle (1T) microcontroller, is a high speed, low power consumption, strong anti-interference of a new generation of $8051 \mathrm{MCU}$, instruction code is fully compatible with the traditional 8051, but fast 8-12 times. Internal integrated MAX810 dedicated reset circuit, 2 way PWM, 8 high speed 10 bit A/D conversion ( 250 thousand times / sec) [8-9].

Introduction of Ultrasonic Module. The module parameters of ultrasonic distance measurement are shown in Table 1, the working voltage is DC $5 \mathrm{~V}$, the working frequency is $40 \mathrm{KHz}$, the range is $2 \mathrm{~cm}-3.5 \mathrm{~m}$. A range of data sent to the microcontroller baud rate to 9600 .

Table 1 Parameters of ultrasonic distance measurement module

\begin{tabular}{|c|c|}
\hline Electrical parameters & Ultrasonic module \\
\hline working voltage & DC 5V \\
\hline Working current & $15 \mathrm{~mA}$ \\
\hline Working frequency & $40 \mathrm{KHz}$ \\
\hline Information of range & $2 \mathrm{~cm}-3.5 \mathrm{~m}$ \\
\hline resolution & $1 \mathrm{~mm}$ \\
\hline Angle of measure & 15 度 \\
\hline baud & 9600 \\
\hline
\end{tabular}

The formula for the distance is expressed as: 
$\mathrm{L}$ is the length of the distance; $\mathrm{C}$ is the ultrasonic propagation velocity in the air; $\mathrm{T}$ is the measurement of the time difference between the spread ( $\mathrm{T}$ for the launch to receive the time value of half). Known ultrasonic velocity $\mathrm{C}=344 \mathrm{~m} / \mathrm{s}$ (at $20 \mathrm{DEG} \mathrm{C}$ at room temperature), the ultrasonic propagation velocity by the density of the air, the higher the density of the air is the ultrasonic propagation speed faster, and the density of the air and temperature and has a close relationship, approximate formula is:

\section{$\mathrm{C}=\mathrm{C} 0+0.607 * \mathrm{~T}$}

In the formula: $\mathrm{C} 0$ is zero when the sound wave speed $332 \mathrm{~m} / \mathrm{s}$; $\mathrm{T}$ for the actual temperature (C). In order to make the ultrasonic ranging precision reach $1 \mathrm{~mm}$, we must consider the environment temperature of ultrasonic wave propagation. The temperature value is read by the DS18B20 acquisition circuit.

\section{Software Programming}

Software Flow Chart. Software flow chart as shown in Fig. 2, first of all initialization 1602 and timer, timer initialization for $10 \mathrm{~ms}$ interrupt time, then every $10 \mathrm{~ms}$ read temperature and serial data a, according to the formula calculated distance value and the result is sent to display 1602 .

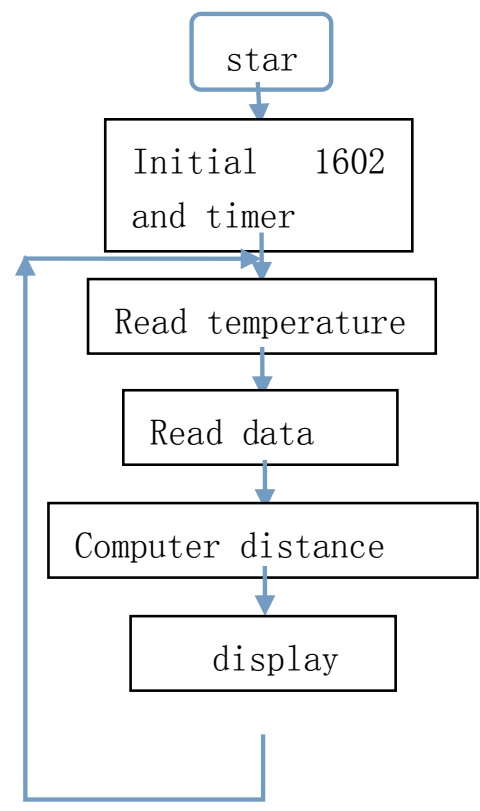

Figure 2. Software flow chart

Part of the Code. Software using C language programming, compiler development environment is IAR5.0 [10]. Temperature compensation calculated from the serial port to read the data format is



OXFF: start data for a frame, used to determine.

H_DATA: high 8 bits of distance data.

L_DATA: 8 bit low distance data.

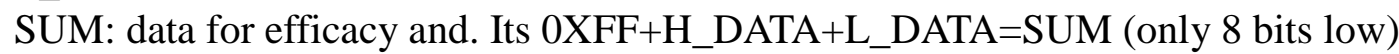

H_DATA and L_DATA consist 16 bits of data, the value of the distance in millimeters. The data is converted to the distance code as follows:

void conversion(uint temp_data)

$\{$ disbuff $[0]=$ temp_data/1000;

disbuff[1]=temp_data\%1000/100;

disbuff[2]=temp_data\%1000\%100/10;

disbuff[3]=temp_data\%1000\%10\%10; 


\section{Test Results}

According to the above description of the design of the hardware circuit and debugging is completed, with the $\mathrm{C}$ language software programming, display the results as shown in Fig. 3:

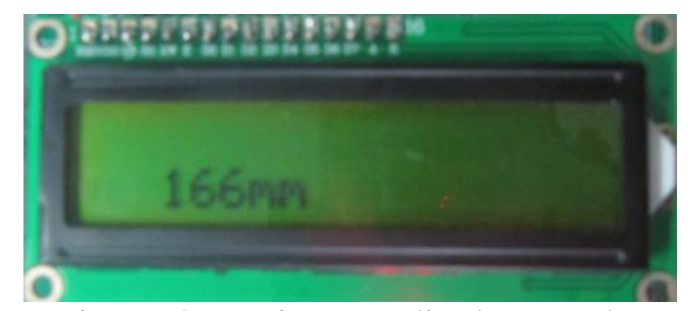

Figure 3. Distance display results

After a number of measurements, the following data, as shown in table 2:

Table 2 measurement results

\begin{tabular}{|l|l|l|l|l|l|l|l|l|l|}
\hline $\begin{array}{l}\text { Real } \\
\text { distance }\end{array}$ & $\begin{array}{l}25 \mathrm{~m} \\
\mathrm{~m}\end{array}$ & $50 \mathrm{~mm}$ & $75 \mathrm{~mm}$ & $\begin{array}{l}125 \mathrm{~m} \\
\mathrm{~m}\end{array}$ & $\begin{array}{l}166 \mathrm{~m} \\
\mathrm{~m}\end{array}$ & $215 \mathrm{~mm}$ & $\begin{array}{l}250 \mathrm{~m} \\
\mathrm{~m}\end{array}$ & $\begin{array}{l}285 \mathrm{~m} \\
\mathrm{~m}\end{array}$ & $350 \mathrm{~mm}$ \\
\hline $\begin{array}{l}\text { measure } \\
\text { d value }\end{array}$ & $\begin{array}{l}25 \mathrm{~m} \\
\mathrm{~m}\end{array}$ & $\begin{array}{l}50.8 \mathrm{~m} \\
\mathrm{~m}\end{array}$ & $\begin{array}{l}74.2 \mathrm{~m} \\
\mathrm{~m}\end{array}$ & $\begin{array}{l}124 \mathrm{~m} \\
\mathrm{~m}\end{array}$ & $\begin{array}{l}166 \mathrm{~m} \\
\mathrm{~m}\end{array}$ & $\begin{array}{l}215.2 \mathrm{~m} \\
\mathrm{~m}\end{array}$ & $\begin{array}{l}251 \mathrm{~m} \\
\mathrm{~m}\end{array}$ & $\begin{array}{l}286 \mathrm{~m} \\
\mathrm{~m}\end{array}$ & $\begin{array}{l}350.5 \mathrm{~m} \\
\mathrm{~m}\end{array}$ \\
\hline
\end{tabular}

\section{Concluding Remarks}

This paper describes the principle and method of ultrasonic distance measurement, and draws the schematic diagram, produced the PCB printed circuit board, the printed circuit board debugging, according to the software process $\mathrm{C}$ language programming Experimental results show that the accuracy of distance measurement can be realized by ultrasonic wave, and the error is less than $1 \mathrm{~mm}$, which can be widely used in intelligent vehicle, robot and other equipment.

\section{Reference}

[1] Wang Jihong. High precision micro pressure measurement with ultrasonic wave and its application: [Thesis] Shanghai: Tongji University, 2008

[2] Liao Ping; Wu Yuesong; Wang Peng; Yue Lili. A large range of ultrasonic distance measurement system based on CAN bus, instrument technology and sensor

[3] [J].2014,10:62-65

[4] Yao Yongping.STC12C5A60S2 Series MCU manual [M], macro crystal technology, 2011,8-9

[5] Tang Sichao. Embedded system software design based on Embedded Workbench [M]. IAR Beijing: Beihang University press, 2010

[6] Guo Qing. Design of ultrasonic distance measuring system based on STC89C52, instrument technology and sensor [J].2011,6:74-77

[7] Wang Zhenbin, Liu Jiayou et al. Optimization of extraction process of fig polysaccharide and its ultrasonic modification [J], Chinese Journal of agricultural engineering, 2014,30 (10): 262-269

[8] Zeng Wei, Wang Haitao, et al. Research on laser ultrasonic defect detection based on energy analysis [J], Chinese Journal of instrument and meter, 2014,35 (3): 650-655

[9] Li Changlu, Su Hansong. Research on [J] ultrasonic positioning system, laboratory research and exploration, 2013, 32 (2): 39-44. 
[10]Chen Jian, Sun Xiaoying, Lin Lin, Wang Bo. Detection method of a kind of high precision ultrasonic wave arrival time [J], Journal of the instrument and meter, 2012,33 (11): 2422-2428

[11]Li Bin Chen Jieyu. Comparison method based on double threshold method for ultrasonic flowmeter signal processing [J], Journal of electronic measurement and instrument, 2013,27 (11): 1024-1033 